Wohlfeilere Bereitungsart des Merlur- und Bleijodids. 303

Volum des Gases später ab und liess nun das Stickoxyd von Eisenoxydulsalzlösung absorbiren, worauf der von der Luft, die mit der Baumwolle eingeführt war, herrührende rïckständige Stickstoff gemessen und mit in Rechnung gebracht wurde. (Phil. Mag. Journal. Vol. 30. Pharm. Centrbl. 1847. No. 13).

$B$.

\title{
Ueber das Phosphamid.
}

Die folgende Reaction des Phosphamids bestätigt die Zusammensetzung desselben, welche schon früher von Gerhardt angegeben worden ist. Wenn man das Phosphamid mit einer Schwefelsäure, die mindestens so viel Wasser enthält, als das Hydrat $\mathrm{SO}^{2} \mathrm{HO}+1 \frac{1}{2} \mathrm{HO}$ erfordert, erwärmt, so löst es sich darin ohne alle Gasentwickelung auf und nach Verlauf einiger Tage setzen sich daraus farblose Krystalle von zweifach-schwefelsaurem Ammoniak ab, die man nur mit Weingeist zu waschen braucht, um sie ganz rein zu haben. Die rückständige Mutterlauge fällt die Silberlösung gelb und enthält also Phosphorsäure. Das Phosphamid in den ublichen Aequivalenten $=\mathrm{PH}^{3} \mathrm{~N}^{2} \mathrm{O}^{2}$ genommen, hat man:

$$
\begin{aligned}
& \mathrm{PH}^{3} \mathrm{~N}^{2} \mathrm{O}^{2}+4\left(\mathrm{SO}^{3} \mathrm{HO}+1 \frac{1}{2} \mathrm{HO}\right) \\
& \left.=2\left(2 \mathrm{SO}^{3} \mathrm{HO}, \mathrm{NH}^{3}\right)+\mathrm{PO}^{3} \mathrm{HO}\right) .
\end{aligned}
$$

(Ann. de Chim. et de Phys. 3 Ser. - Pharm. Centralbl. 1847. Nr. 38.)

$B$.

\section{Wohlfeilere Bereitungsart des Merkur- und Bleijodids.}

Gaff ard, Apotheker zu Aurillac (Departement Cantal), macht folgende Vorschriften bekannt, weil sie sich bei dem hohen Preise des Jods durch ihre Wohlfeilheit empfehlen. was leicht einzusehen ist, da nach andern Verfahren Kaliumjodid angewandt wird, welches, obgleich es nur 75 an Jod enthält, doch eben so viel kostet als dieses. Uebrigens giebt Gaffard's Methode ein stets gleichförmiges Product. Sie ist folgende für Bleijodid:

$$
\begin{aligned}
& \text { Jod ........ } Z^{\mathrm{v}} \\
& \text { Eisenfeile..... } 3_{\mathrm{j}} \mathrm{Z} \mathrm{ij} \\
& \text { Bleiacetat.... } \zeta_{\mathrm{j} \beta} \beta \text { (krystallisirtes). }
\end{aligned}
$$

Das Jod und die Eisenfeile werden mit 20 Unzen Wasser iubergossen, und gelinde so lange erwärmt, bis die Fliussigkeit farblos erscheint, worauf man sie filtrirt; dann wird obige Menge des Acetats in 16 Unzen Wasser gelöst, und mit etwas Essigsäure übersäuert. Man giesst beide Auflösungen zusammen, schüttelt sie, und sondert den 
Niederschlag mittelst des Filters ab. Es bleibt zwar noch eine Spur von Eisenjodid unzersetzt in der Flussigkeit, was aber nicht schadet, da es ein zu andern $\mathrm{Z}$ wecken nutzbares basisches Jodid geben kann.

Für Merkurjodid:

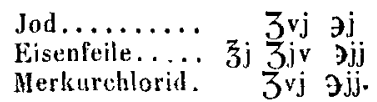

Die Eisenjodürsolution wird, wie oben erwähnt, bereitet, das Merkurjodid in 20 Unzen Wasser gelöst. Man giesst erstere Auflosung in die letztere, schiittelt und filtrirt. Der im Filter bleibende Rückstand wird gewaschen, getrocknet etc. (Journ. de Pharm. d'Anvers. Aoüt. p.381. 1817.)

du Mênil.

\section{Ueber die grosse Verbreitung des Platins.}

Dr. M. Pettenkofer ist durch zahlreiche Erfahrungen zu dem Schlusse gelangt, dass das Platin ein ebenso allgemein verbreitetes Metall sei, als das Gold, und dass namentlich alles im Handel und Wandel vorkommende Silber, welches nicht etwa direct aus einer Scheidung stammt, Platin enthalte, und dass auch die meisten Kupfererze platinhaltig sind, hat M. Herzog von Leuchtenberg neuerdings nachgewiesen.

Der Platingehalt älterer Münzen, welche alle zu einer Zeit geprägt wurden, wo das Platin an und für sich noch gar keine Anwendung, mithin auch keine Verbreitung durch den Handel erlangt hatte, lässt schliessen, dass es schon in dem Bergsilber enthalten sein musste, woraus sie hergestellt worden sind. Das aus alten Thalern gewonnene Gold, so wie das gewöhnlicher Goldscheidungen, enthält in der Regel 2-3 Tausendstel Platin.

Um das Platin darin nachzuweisen, schmilzt man das Scheidegold, aber ohne Zusatz von Salpeter, legirt dann $1 \mathrm{Grm}$. davon mit $2-2 \frac{1}{2}$ Theilen reinen Silbers und verfährt ganz so, wie bei einer gewöhnlichen Goldprobe Die hierbei erhaltene salpetersaure Silberlösung fällt man mit verduinnter Salzsäure, filtrirt das Chlorsilber $a b$ und dampft die Fluissigkeit, zuletzt im Wasserbade, bis zur Trockne ein; der Rückstand wird mit Weingeist behandelt und aus der Lösung das Platin durch Salmiak gefältt. Zur quantitativen Bestimmung kocht man nach dem D'Arcet'schen Verfahren zwei mit dem nöthigen Silber beschickte Proben, cine mit Salpetersäure, die andere mit Schwefel- 